\title{
Clinical trials: New developments
}

\author{
Louis-Philippe Boulet MD, President, Canadian Thoracic Society
}

$\mathrm{C}$ anadian respiratory health research is recognized as being among the best worldwide. Many Canadian researchers are leaders in international projects, including large scale clinical trials. There is, however, a need to develop a structure that could foster the collaboration of Canadian investigators in joint projects of this sort. In the past few years, discussions have taken place on what could be a Canadian Thoracic Society (CTS) Clinical Trials Group. This is a wonderful opportunity to put forward such an initiative, in the context of the new Canadian Institutes of Health Research (CIHR), where this type of collaborative activity fits quite well with the goals of this new institution.

However, such a group should not duplicate or compete with current research programs but could be involved in new initiatives that would complement the existing programs. These new initiatives may include questions of interest involving therapeutic or diagnostic trials, or cohort studies addressing questions on the clinical course or prognosis of a specific disease, particularly on rare conditions or in trials requiring large numbers of subjects. Priority could be given to studies that would have the most impact on respiratory health.

Discussions of a CTS Clinical Trials Group have taken place over the past two years and more intensely in the past few months. A working document has been proposed by the CTS to the Canadian Lung Association (CLA). The goals of this initiative are to promote national, collaborative multicentre research of clinically important issues arising in adult and pediatric pulmonary medicine; such a group might, for example, elaborate or support studies needed to increase the level of evidence or to set key recommendations for treatment guidelines. Hopefully, this will attract additional funding for Canadian collaborative research and increase the collaboration with the CIHR to determine which priorities to promote in regard to respiratory health research in Canada.
Parallel to the CTS initiative, the CLA is considering the development of an infrastructure that could support some phase 3 and 4 trials that are not covered by the CTS initiative. At the CLA Board meeting in June 2000, a committee was asked to investigate further and develop a recommendation for the Board regarding clinical trials. The Clinical Trials Committee presented the following recommendations to the CLA Board of Directors on September 23.

- The CLA will support the CTS proposal in principle and will ask them to advance it.

- The CTS will support the CLA proposal provided that CTS membership involvement is voluntary.

- The CLA/CTS will allow legal counsel to develop a draft framework for a new corporation.

- Net profit after expenses will flow back into research for the first five years, after which time a review will take place.

At the last CTS Board meeting, it was agreed that all Canadian institutions with a respiratory program will have the opportunity to select a representative to the working group that will develop the structure and terms of references of the Clinical Trials Committee, which will be another ad hoc committee of the CTS.

The CTS hopes that this initiative will progress quickly and will rapidly lead to concrete accomplishments. 


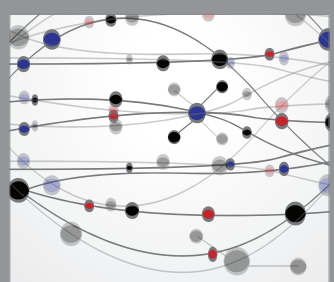

The Scientific World Journal
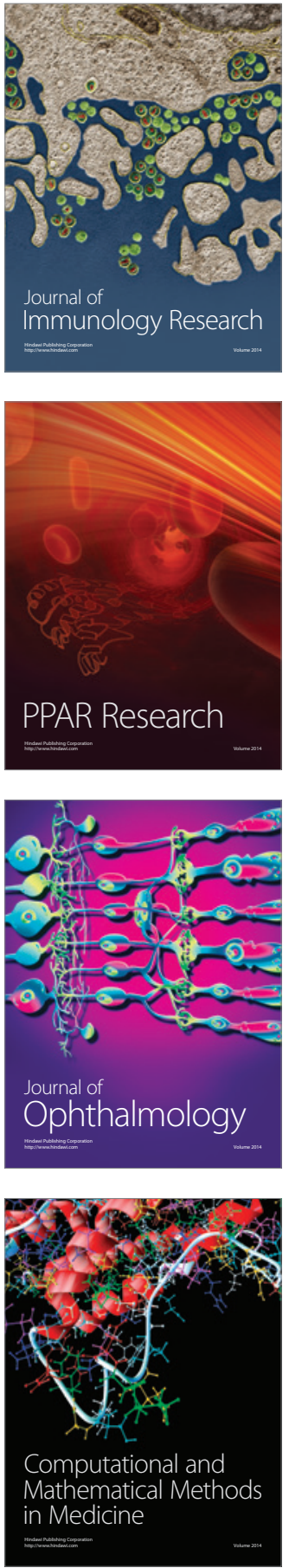

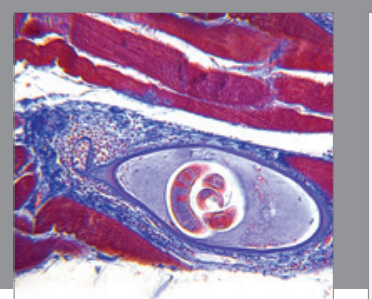

Gastroenterology Research and Practice

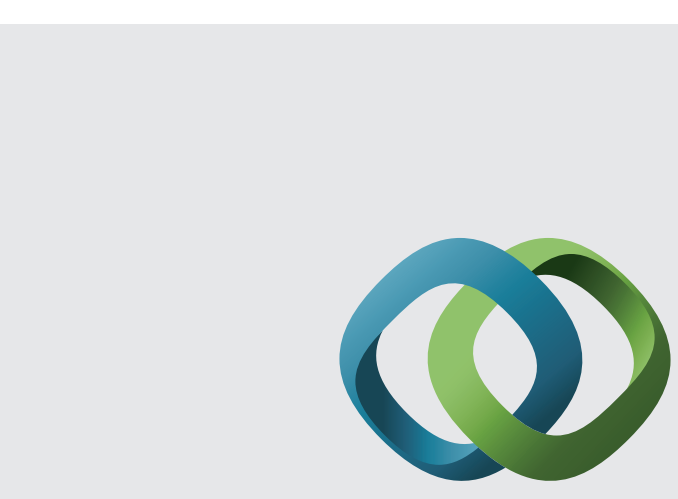

\section{Hindawi}

Submit your manuscripts at

http://www.hindawi.com
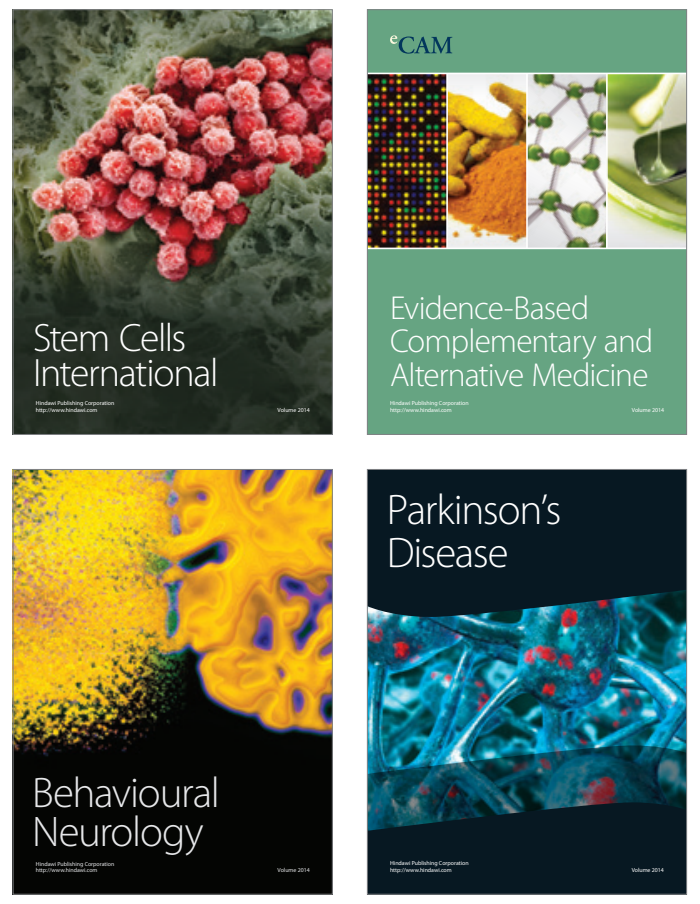
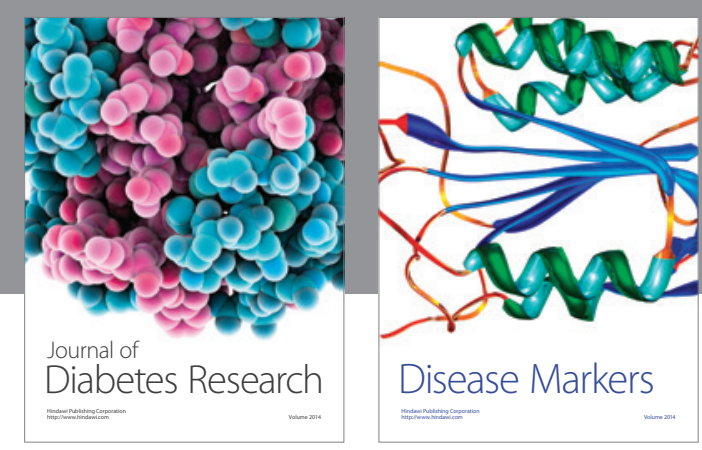

Disease Markers
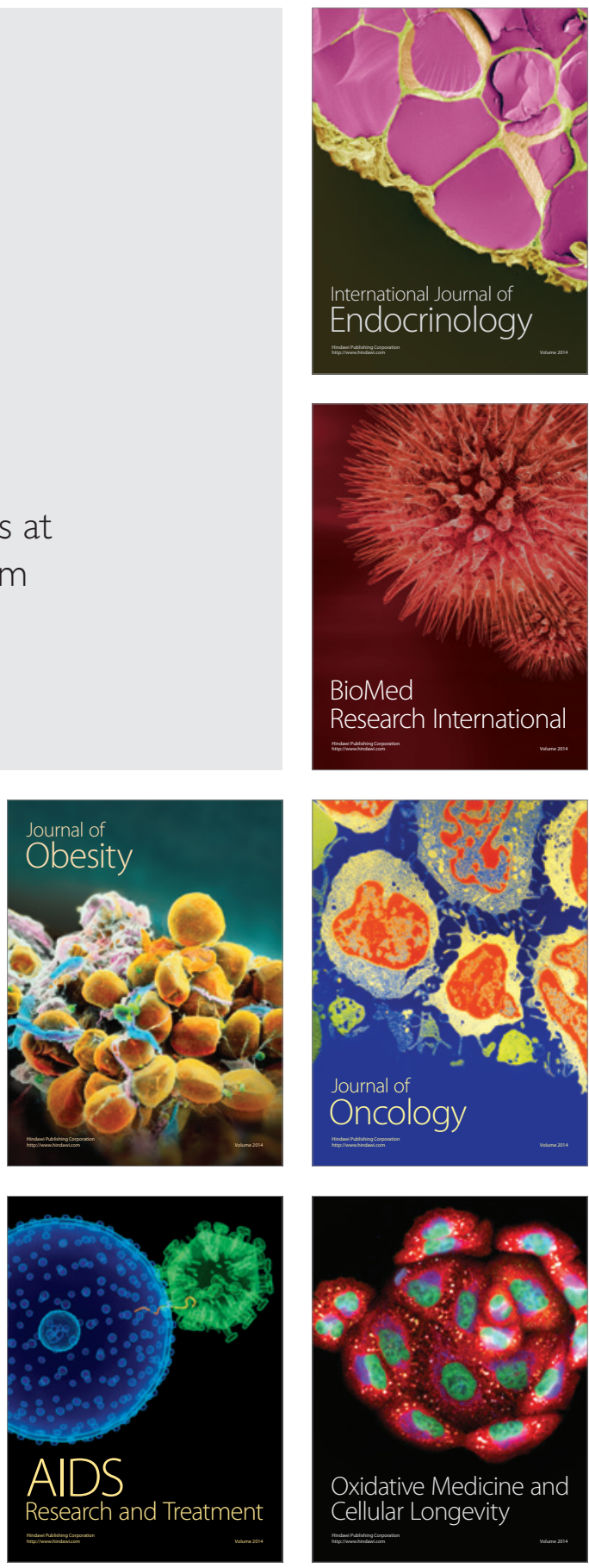